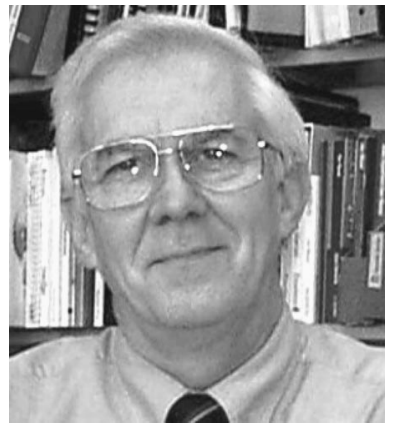

\section{An International Society}

During the past few years that I have served on the Board of Directors of SPIE, it has become clear that the word "International" in our name has taken on increasing importance. From what began as a society of American engineers doing high-altitude photography, mostly for the U. S. Department of Defense, SPIE (the pronunciation "spy" was quite appropriate then) has become a society with members from all fields of optics and its applications. (SPIE really stands for the "Society of People Interested in Everything.' ') They come from all sectors of public life: academia, commerce, and government. And they reside all over this planet.

The Society now has 20 chapters in 17 countries, with over 1,400 chapter members. Since the Society's beginning in the United States over four decades ago, there has been a remarkable growth in the number of SPIE members outside the United States. Today, over 4,700 of SPIE's 14,800 members are from 75 countries other than the U.S. Six of the 13 members of the current Board of Directors are non-U.S. members and our immediate PastPresident, Roland Jacobsson, is from Sweden. As this international participation has increased, any deliberations regarding initiatives that were purely American (or even North American) were given additional scrutiny. Questions arise. Should we lend our prestige and support to a purely U.S. initiative or petition?

For example, SPIE participates jointly with OSA in the Congressional Fellows program. Our two societies sponsor an engineer or scientist to serve as a technical aide for a U.S. congressman. This is a competitive process in which members are nominated and chosen by a Society committee. Two of our members, Duncan Moore and Carmiña Londoño, were OSA Congressional Fellows. (At the time that they entered the program SPIE had not yet entered into the joint sponsorship agreement.) Both, by the way, have moved into government after their stint on Capitol Hill. Carmina is now at the National Institute of Standards and Technology (NIST) and Duncan is at the White House.

Another example of SPIE's participation in an American project was its collaboration on the report "Harness- ing Light: Optical Science and Engineering for the 21st Century' by the Committee on Optical Science and Engineering (COSE). A number of SPIE members and staff attended meetings and contributed to its content. This report, commissioned by the U.S. National Academy of Sciences, evaluated the current impact of optical science and engineering in the U.S. and projected trends and needs into the future. (If you haven't seen or heard of the report, you can find a summary on the Web at http:// books.nap.edu/html/harnessing/\#sum).

I have no recollection of any extensive discussions of the international impact of various initiatives during my first period on the Board as an elected member. But recently any effort involving public policy is examined carefully. At every SPIE Board meeting I have attended in the past few years, I have asked myself a question: Is this an appropriate project for an international society?

In most cases the answer is "'yes.' ' In conjunction with a Board meeting in Stockholm in October 1998, Art Guenther, one of the SPIE members on the COSE committee, presented an overview and answered questions for the members of the Swedish Optical Society. The report was eagerly received by those attending the briefing. It was seen as a valuable resource for research and planners in establishing the importance of optics in Sweden. But other initiatives such as Congressional Visits Day and a Congressional Fellow might not seem as applicable. Or so I thought.

In July I was invited by the Australian Optical Society (AOS) to come to Sydney and participate in their annual meeting. This invitation was part of a Memorandum of Understanding between SPIE and the AOS that specifies that every two years the vice president/president-elect will attend the AOS meeting with partial support from SPIE. A similar agreement with OSA brought Erich Ippen, my OSA counterpart, to Sydney, too. From my interactions with the leadership of the AOS and conference participants, it is clear that these visits help to fulfill SPIE's international mission.

With the exception of the few international guests, the conference participants were mainly researchers from Australia and New Zealand. I was impressed by the exceptionally high quality of the papers. Connected to the rest of their colleagues by strenuous travel, e-mail and 
Internet, their work is timely and inventive. One very moving event during the conference was the posthumous award of the AOS Medal to Dan Walls. Peter Drummond, a student of Dan's, gave a loving appreciation of Dan's work and his personality.

In my discussion with those in the leadership of the AOS, I was told that the funding of research in Australia was becoming scarce, despite documented proof that this research had paid dividends to their economy. Taking a page out of our public affairs efforts, the AOS are organizing a parliamentary visitation day to plead the good efforts and effects of optics research in Australia. We hope to be able to supply the AOS with some of the procedures and materials used in our visitation days. So, some of our public affairs efforts are extensible and ap- plicable to Chapters and collaborating societies overseas. Perhaps, the AOS may someday, in collaboration with other professional societies, sponsor a Parliamentary Fellow.

After I ask my first question: Is this an appropriate project for an international society?, there is a second question: Could SPIE members in optical engineering outside the U.S. translate this initiative for their own use? If the answer is "yes," then it should be given serious consideration by our international society.

Donald C. O'Shea Editor 